\title{
Design of a contactless body temperature measurement system using arduino
}

\author{
Asif A. Rahimoon ${ }^{1}$, Mohd Noor Abdullah' ${ }^{2}$, Ishkrizat Taib ${ }^{3}$ \\ ${ }^{1,2}$ Green and Sustainable Energy (GSEnergy) Focus Group, Faculty of Electrical and Electronic Engineering, \\ Universiti Tun Hussein Onn Malaysia, Malaysia \\ ${ }^{3}$ Additive Manufacturing Research Group (ADDMAN), Department of Manufacturing and Industrial Engineering, \\ Faculty of Mechanical and Manufacturing Engineering, Universiti Tun Hussein Onn Malaysia, Malaysia
}

\begin{tabular}{|c|c|}
\hline Article Info & ABSTRACT \\
\hline Article history: & \multirow{10}{*}{$\begin{array}{l}\text { The recent advances in electronics and microelectronics devices allow } \\
\text { the development of newly low-cost monitoring tools used by peoples for } \\
\text { health preventive purposes. Sensors used in medical equipments convert } \\
\text { various forms of human body vital signs into electrical signals. Therefore, } \\
\text { the healthcare monitoring systems considering non-invasive and wearable } \\
\text { sensors with integrated communication mediums allow an efficient solution } \\
\text { to live a comfortable home life. This paper presents the remote monitoring of } \\
\text { human body temperature (HBT) wirelessly by means of Arduino controller } \\
\text { with different sensors and open source internet connection. The proposed } \\
\text { monitoring system uses an internet network via wireless fieldity (wifi) } \\
\text { connection to be linked with online portal on smart phone or computer. } \\
\text { The proposed system is comprised of an Arduino controller, LM-35 (S1), } \\
\text { MLX-90614 (S2) temperature sensors and ESP-wifi shield module. } \\
\text { The obtained result has shown that real time temperature monitoring data can } \\
\text { be transferred to authentic observer by utilizing internet of things (IoT) } \\
\text { applications. The findings from this research indicates that the difference of } \\
\text { average temperature in between Sensor S1 and S2 is about } 15{ }^{\circ} \mathrm{C} \text {. }\end{array}$} \\
\hline Received Feb 22, 2020 & \\
\hline Revised Apr 9, 2020 & \\
\hline Accepted Apr 17, 2020 & \\
\hline Keywords: & \\
\hline Arduino & \\
\hline ESP-shield & \\
\hline Hyperthermia monitoring & \\
\hline Temperature sensor & \\
\hline & \\
\hline
\end{tabular}

Copyright $\odot 2020$ Institute of Advanced Engineering and Science. All rights reserved.

\author{
Corresponding Author: \\ Mohd Noor Abdullah, \\ Green and Sustainable Energy (GSEnergy) Focus Group, \\ Faculty of Electrical and Electronic Engineering, \\ Universiti Tun Hussein Onn Malaysia, \\ Parit Raja, 86000 Batu Pahat, Johor, Malaysia. \\ Email: mnoor@uthm.edu.my
}

\section{INTRODUCTION}

Nowaday's, health monitoring is a global challenge in peoples life time. The comfort of life lies in a healthy condition which effected by environmental and surgical facts. The measurement of human body vital signs is an important to acknowledge the health status. The perfrormance of any work or exercise in hot conditions disturbs the balanced thermal homeostasis state of human body (HB). This balance acknowledges the $\mathrm{HB}$ about physiological and cognitive performance of body [1-3].

The normal body temperature ranges by $36.5^{\circ} \mathrm{C}$ to $37.5^{\circ} \mathrm{C}$ [4]. The status of health below this limit is stated as hypothermia and the status above is refered as fever and hyperthermia conditions. The hyperthermia also refered as tumour conditional stage that ranges more than $38.5{ }^{\circ} \mathrm{C}$ [5-7]. The individual body temperature measurement is dependent of different aspects i.e. age, exertion, infection and place of body at which measurment made. There are several methods to measure the HBT i.e. oral, retal and axillary through mercurial and contactless thermometers $[8,9]$.

The measurment of HBT with mercurial thermometer is crucial than contactless like as broken of thermometer if bitten during oral measurementm, injury of rectum during rectal measurement. Although, 
researcher are focusing to present digital and contacless thermometer for HBT measurement linealy. Therefore, this paper presents the contactless Infrared based HBT measurement prototype. The paper is organised as follows: in Section 2 a detailed description on the system importance is provided. In Section 3, implementation and demonstrate the hardware and software used for system design is discussed while Section 4 present the output results of experimental setup.

\section{NEED OF TEMPERATURE MONITORING SYSTEM}

The variation in human body temperature (HBT) can lead to different disease. It is essential to quantify the the range of temperature as shown in Figure 1. As stated by researchers that, while evaluating and measuring the health status specially HBT, some vital points are necessary [7, 10-12]. Few measurement methods are shown in Figure 2, while some aspects are justified in sub-sections 2.1 and 2.2 respectively and linked are listed in Table 1.

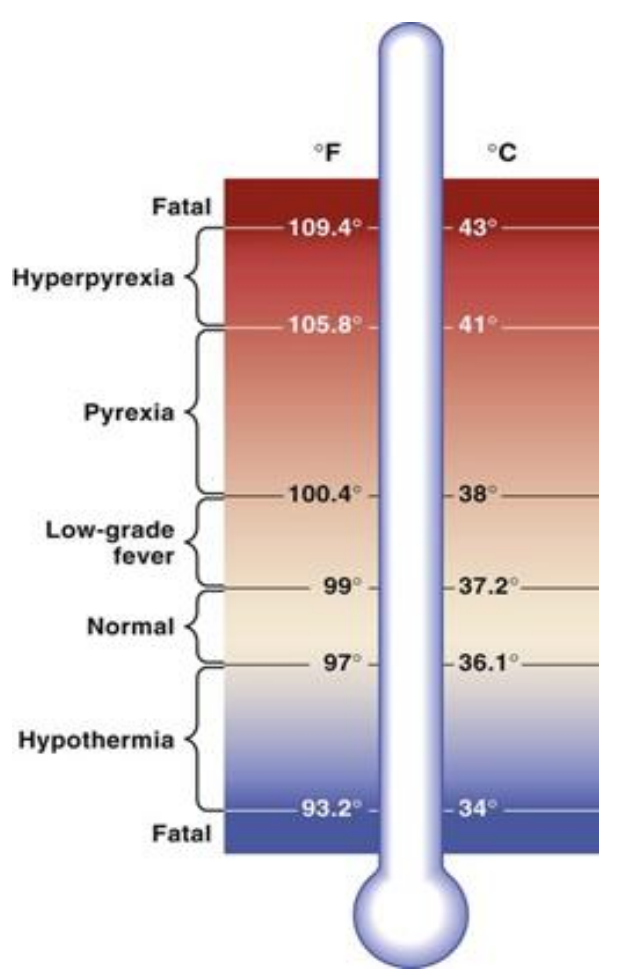

Figure 1. Body temperataure measurement range

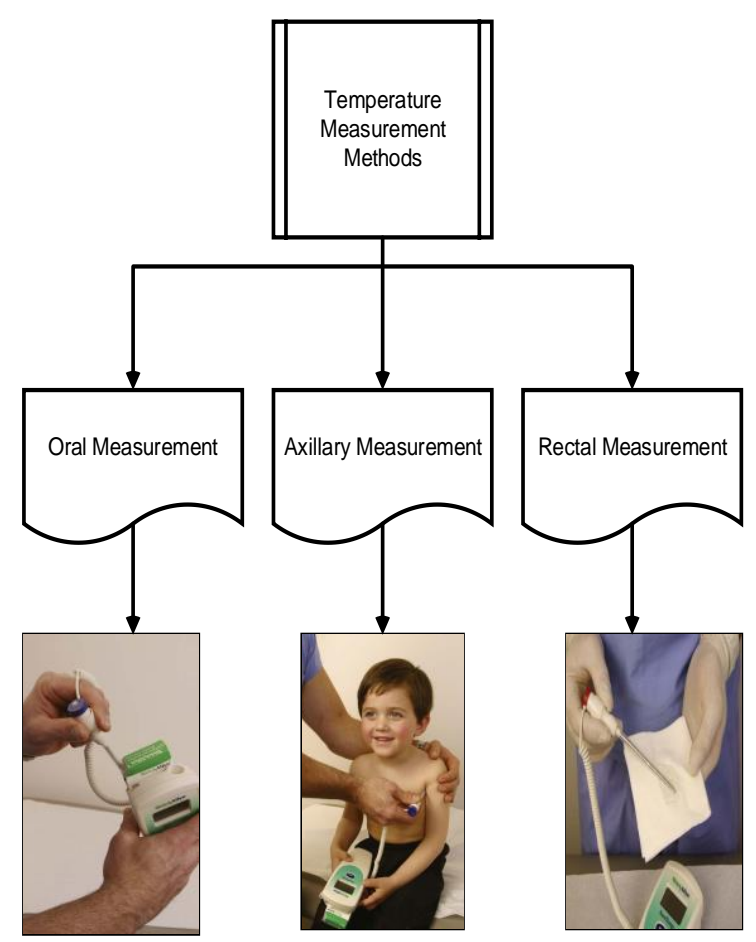

Figure 2. Temperature measurement methods

\subsection{Diurnal variations}

This variation is dependent of human body metabolism. During the sleep the metbolism is slower as decrement in contractions of muscles.

\subsection{Emotional states}

These variations frequently observed with young childrens during extreme anger and crying state which increase the body temperature.

Table 1. Variations in body temperature by age

\begin{tabular}{ccc}
\hline Age Level & Method & Average temperature ${ }^{\circ} \mathrm{C}$ \\
\hline Newborn & Axillary & $36.1^{\circ} \mathrm{C}-37.8^{\circ} \mathrm{C}$ \\
1 year & Oral & $37.6^{\circ} \mathrm{C}$ \\
5 year & Oral & $37^{\circ} \mathrm{C}$ \\
& Oral & $37^{\circ} \mathrm{C}$ \\
Adult & rectal & $37.5^{\circ} \mathrm{C}$ \\
& Axillary & $36.4^{\circ} \mathrm{C}$ \\
Over 70 years & Oral & $36^{\circ} \mathrm{C}$ \\
\hline
\end{tabular}


To attain the perfect health status, balance relationship among core body temperature (CBT) and skin temperature (ST) by non-invasive methods had been attempted [9, 12-14]. The prediction of CBT through chest measurement requires professional equipments for longer-term and continuous monitoring in natural habitats or daily environment. While, the prediction ST with and without external parameters i.e (humadity) was performed with a patch-type device (PTD) attached over the clavicle point of skin [15]. Although the relationship between perspiration rate and ST was also focused to monitor and measure the temperature but the applied PTD was not feasible for long-term use as the monitoring error was $15 \%$ larger than the commercial device.

The monitoring and measurement of ST can be performed with contact and contacless methods i.e utiliziation of arduino controller [16-24], a wireless sensor technology incorporating radio frequency technology (RFT) [25] and android application [26]. These developed measuring prototypes were not suitable to use on large scale applications due to the designing limitation. Furthermore the development in electronic circuitry moves the focused the researcher for smart measuremnt using smart watches and thermoregulator tools. Therefore to measure the human body vital sign the need of measurement tool is essential. This research only limited with temperature measurement using Arduino. The concerned tools to design the proposed health monitoring system are discussed in section 3.

\section{SYSTEM OVERVIEW}

The functional block diagram of proposed system is shown in Figure 3. The proposed system starts with initialization of temperature sensors for collection of real time temperature data in compare to environmental temperature values.

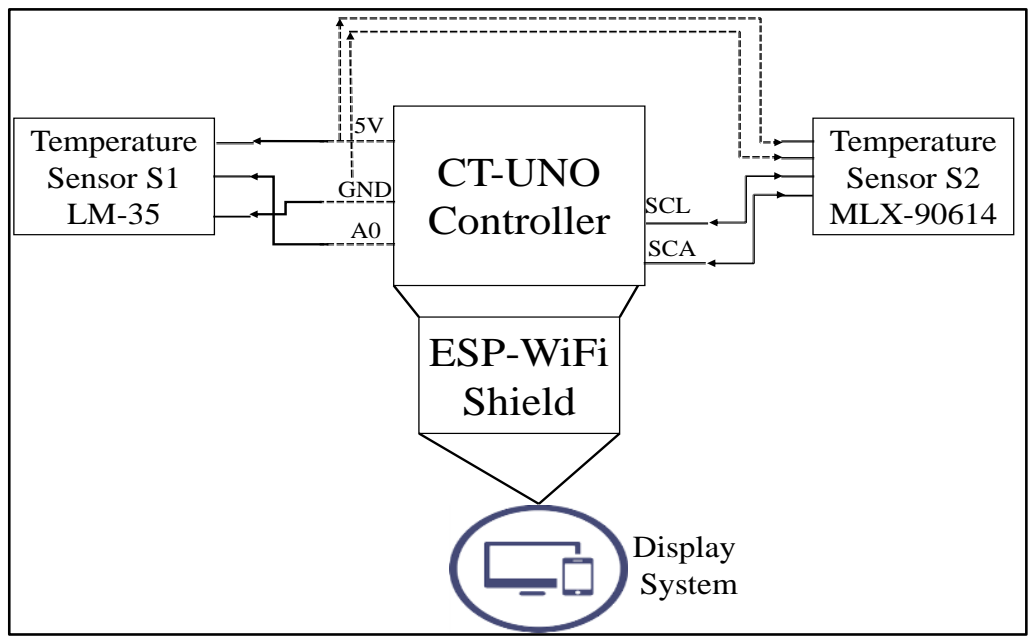

Figure 3. Block diagram of proposed monitoring system

The sensitivity of temperature sensors LM35 (S1) and MLX-90614 (S2) is programmed in C++ language and access through Arduino CT-UNO controller. The ports of configured wifi shield is powered from $5 \mathrm{~V}$ internal supply of CT-UNO controller to transfer the collected data ay online portal. This system is designed without push button scheme to attain the wireless monitoring of temperature. The connective parts of the proposed prototype are expressed in sub-sections 3.1, 3.2 and 3.3 respectively.

\subsection{Arduino CT-UNO controller}

The applied CT-uno is one type of Arduino Mega controller. This microcontroller is based on ATMega328 data sheet consisting of 14 digital input-output pins, 6 pins for pulse width modulation (PWM) outputs and 6 pins for analog inputs. This controller have some auxiliary ports i.e. $16 \mathrm{Mhz}$ oscillator, USB connection and Power jack with reset button. The pins allotted for (S1) and (S2) on Arduino are either A4/A5 in this proposed monitoring system the pin allocations are A0, SDA and SCL respectively for both sensors as shown in Figure 4. The utilization of simple Arduino controller was used for monitoring of the temperature, heart beats, electrocardiography and humadity parameters [13, 20, 27-28]. The CT-UNO controller has reduce the complexity of Arduino mega controller with inclusion of new and simple attached electronic circuitry and utilized in this research work. 


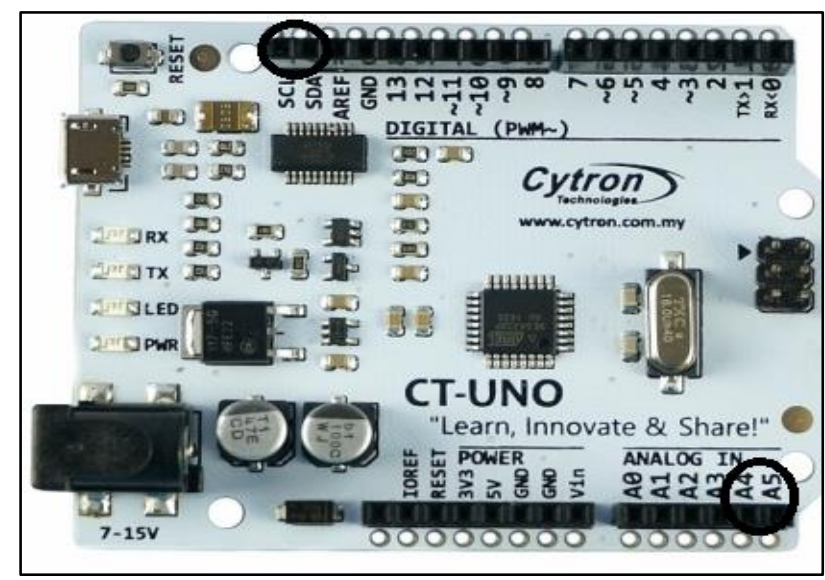

Figure 4. Arduino controller kit

\subsection{Temperature sensor}

The two temperature sensors LM35 (S1) a contact type and MLX-90614 (S2) contactless are used in this proposed monitoring system as shown in Figure 5. The LM35 sensor is a precise sensor which directly converts the output voltage into temperature in Celsius. This conversion is programmed into Arduino panel using the (1). This sensor is better than thermistor due to linear output and low impedance advantages. The range of this sensor is between $-55^{0} \mathrm{C}$ to $150{ }^{\circ} \mathrm{C}[18]$.

$$
\text { Output Temp in }{ }^{o} \mathrm{C}:=\text { Temp } \times 0.48828125
$$

This equation normally used for S1 sensor while assembling with Arduino controller and stated numerical value represent the ratio of input voltage and analog value [23]. The linearity of this S1 sensor is $10 \mathrm{mV} /{ }^{\circ} \mathrm{C}$. While, the Infrared sensor (S2) manufactured by melexis is also used for measurement of body temperature through PWM output pins. This sensor uses low-noise amplifier, 17bit analog-digital coverter for accurate temperature measurement.

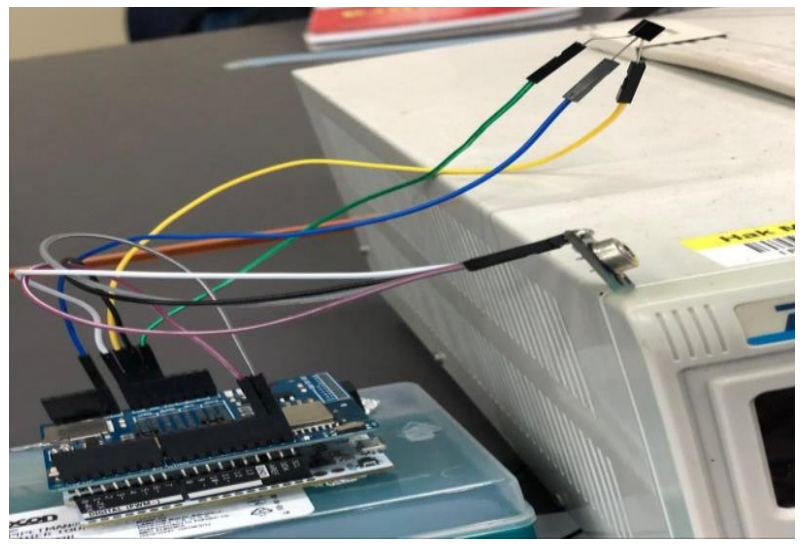

Figure 5. Connectivity of temperature sensors

\subsection{Arduino wifi-sheild}

The Esp-wifi shield is a wireless programable microcontroller that is capable to perform as host or offload wifi network functions. This shield in this research act like as central server hub for transfer and monitoring of collected temperature data. Although researcher also used the Arduino, raspberry pi controller for data monitoring and transferring purpose [28-30]. The comparative analysis of these controller is shown in Table 2. The monitoring can be performed with wire or wireless communication devices to make the designed system reliable considering system protocols [31]. 
Table 2. Comparison of Microcontrollers [29]

\begin{tabular}{cccc}
\hline parameters & Arduino & Raspeberry Pi & ESP-Wifi sheild \\
\hline Processor & ATMega & ARM Cortex-53 & - \\
Operating voltage & $5 \mathrm{~V}$ & $5 \mathrm{~V}$ & $3.3 \mathrm{~V}$ \\
Clock speed & $16 \mathrm{Mhz}$ & $1.2 \mathrm{Ghz}$ & $26 \mathrm{Mhz}-52 \mathrm{Mhz}$ \\
Development Environment & Arduino IDE & & Arduino IDE, Lua Loader \\
Supported Communication & IEEE $802.11 \mathrm{~b} / \mathrm{g} / \mathrm{n}$ & IEEE $802.11 \mathrm{~b} / \mathrm{g} / \mathrm{n}$ & IEEE 802.11 b/g/n \\
\hline
\end{tabular}

The flowchart for the proposed system is shown in Figure 6. The proposed system is powered through CT-UNO to initiate the process of embedded sensors S1 and S2 respectively. The sensitivity of applied sensors is dependant of two factors. i.e placement of sensor and delay time to monitor and measure the obtained data. The proposed monitoring system works in a closed loop strategy. This strategy is followed up after initial setup of sensors to measure the ambient and body temperature. The activation of sensors acknowledge the configured ESP-wifi shield to transfer and display the obtained data to the selected online portal with delay of about 1 minute. This delay is used to verify the system effectiveness in case any interruption or external effects occurs during operating state of applied circuitry. In result, the closed loop will run until all the satisfactory result displayed at online portal.

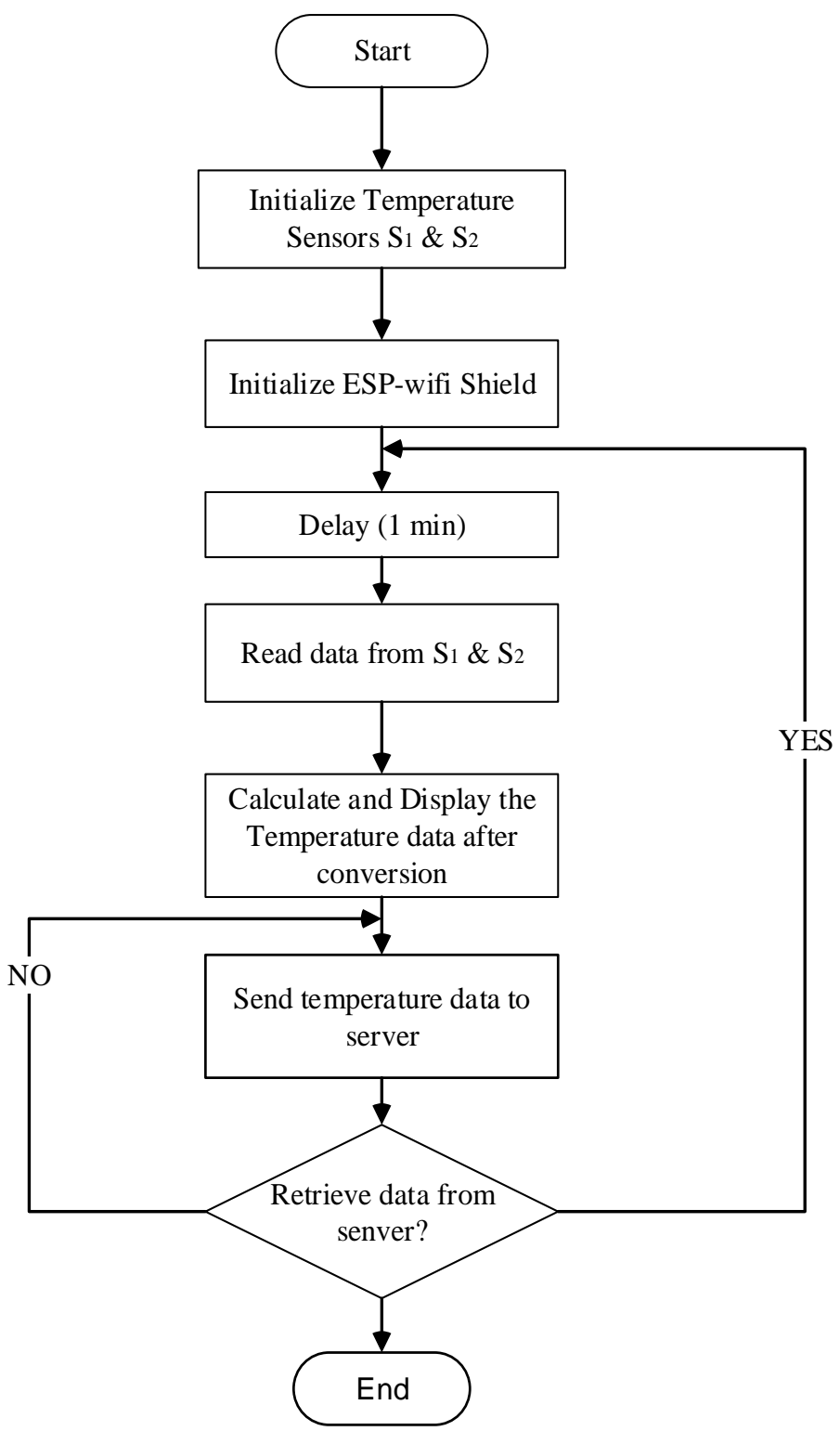

Figure 6. General flow chart of proposed system 


\section{RESULT AND DISCUSSION}

The testing and analyzing of proposed system was performed in UTHM premises on $21^{\text {st }}$ January including an indoor and outdoor environment with recorded ambient temperature of $35.6{ }^{0} \mathrm{C}$. The F2 block with ground to $2^{\text {nd }}$ level longue was selected for experimental setup to monitor the variations in temperature as stated in Figure 7(a-c). At initial, the collection of data is directly monitored with Arduino platform and later was transferred to the online portal using ESP-wifi shield.

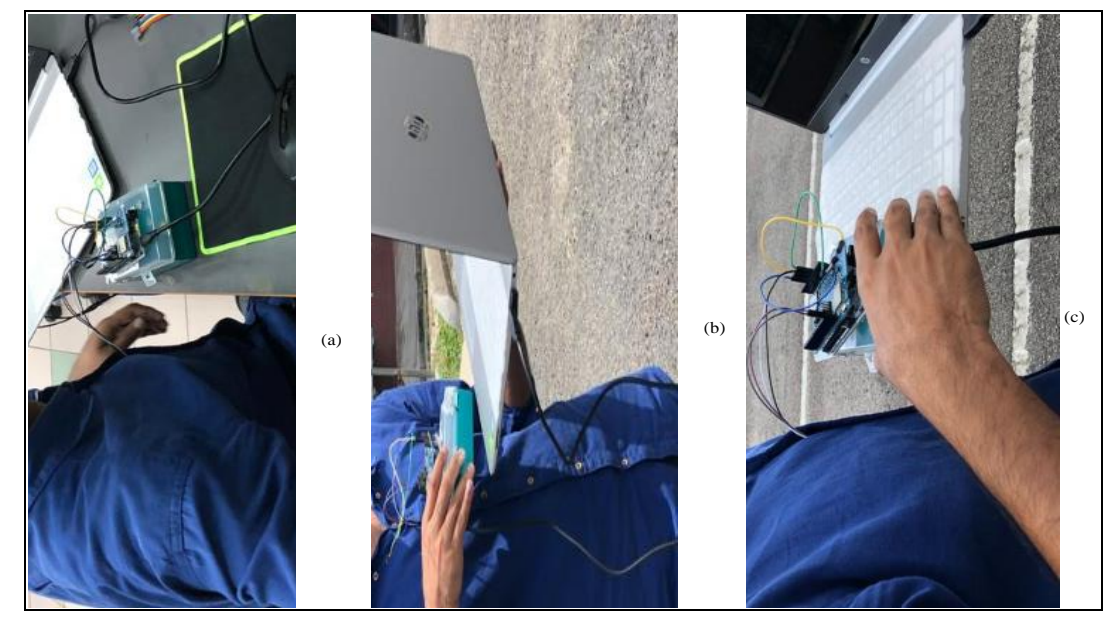

Figure 7(a-c). Measurement with indoor and outdoor environment

The monitored data of temperature sensors LM-35 as sensor 1 (S1) and MLX-90614 (S2) through CT-UNO monitor is slightly differnt due to operating functionality as shwn in Figure 8. Moreover, S1 sense the data in thermal contact otherwise it just observes the surrounding temperature. Similarly, IR based S2 sensor used to measure the body temperature at indoor and outdoor environment.

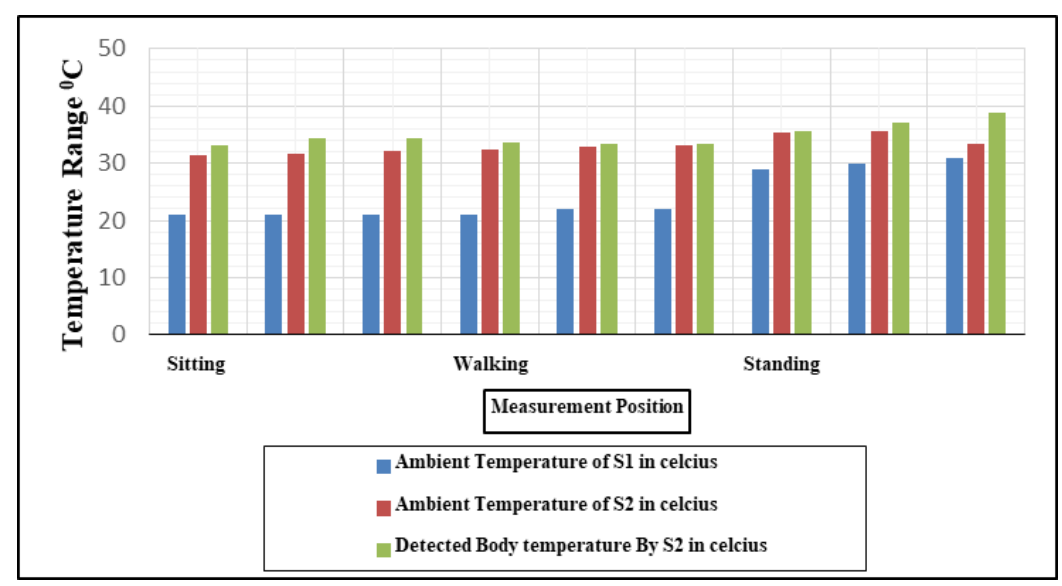

Figure 8. Monitoring result of proposed system

\section{CONCLUSION}

Healthcare organizations i.e. insurance companies need a real-time, reliable and accurate dignositc monitoring system provided by low-cost sensor system application, whether the patient is in hospital or at home. A real time monitoring of body temperature using embedded platform has been presented in this paper. The collection of real time data is controlled by CT-UNO controller. The transferring of sensed data from implemented LM-35 and MLX-90614 temperature sensors at the online portal is performed through ESP-wifi shield. This platform is wirelessly connected to monitor and display the real time data of deployed S1 and S2 sensors respecticvely at indoor and outdoor environment. This deployment clearify the effects of 
elevation in temperature readings which varies due to other environmental aspects i.e humadity, barometer, blood pressure and heart rate that are not considered in this research. The findings from this research indicates the difference in average temperature from $\mathrm{S} 2$ is about $15^{\circ} \mathrm{C}$. Although, the daily monitoring of body temperature can prevent the people from threaten of fever, hypothermia and hyperthermia illness.

\section{ACKNOWLEDGEMENTS}

The authors would like to thank Universiti Tun Hussein Onn Malaysia (UTHM) for supporting this project under Multidisciplinary Research Grant Vot No. H 505.

\section{REFERENCES}

[1] M. A. Miah, et al., "Continuous Heart Rate and Body Temperature Monitoring System using Arduino UNO and Android Device," in International Conference on Electrical Information and Communication Technology (EICT), pp. 183-188, 2015.

[2] N. A. A. Rahman and A. B. Jambek, "Biomedical health monitoring system design and analysis," Indonesian Journal of Electrical Engineering and Computer Science, vol. 13, no. 1, pp. 1056-1064, 2019.

[3] M. Hyland, et al., "Wearable thermoelectric generators for human body heat harvesting," Applied Energy, vol. 182, pp. 518-524, 2016.

[4] A. Almazroa, et al., "Easy Clinic : Smart Sensing Application in Healthcare," in 2019 2nd International Conference on Computer Applications \& Information Security (ICCAIS), pp. 1-5, 2019.

[5] G. C. van Rhoon, et al., "Hyperthermia and the need to monitor temperature," in International Conference on Electromagnetics in Advanced Applications (ICEAA), pp. 1181-1185, 2015.

[6] T. Drizdal, et al., "Prediction of Temperature Distribution for Superficial Hyperthermia Treatment : Accuracy of Temperature Dependent Blood Perfusion Model," in 44th European Microwave Conference, pp. 782-785, 2014.

[7] A. Sohail, et al., "A review on hyperthermia via nanoparticle- mediated therapy," Bulletin du Cancer, vol. 104, no. 5, pp. 452-461, 2017.

[8] H. Tang and K. Hung, "Design of a Non-Contact Body Temperature Measurement System for Smart Campus," in IEEE International Conference on Consumer Electronics-China (ICCE-China), pp. 1-4, 2016.

[9] N. Nowshin, et al., "Designing and Implementation of Microcontroller Based Non-Invasive Health Monitoring System," in 2019 International Conference on Robotics,Electrical and Signal Processing Techniques (ICREST), pp. 134-139, 2019.

[10] J. Choi and V. Loftness, "Investigation of human body skin temperatures as a bio-signal to indicate overall thermal sensations," Building and Environment, vol. 58, pp. 258-269, 2012.

[11] S. Wang, et al., "A Mach-Zehnder interferometer-based High Sensitivity Temperature sensor for human body monitoring," Optical Fiber Technology, vol. 45, pp. 93-97, 2018.

[12] R. Niedermann, et al., "Prediction of human core body temperature using non-invasive measurement methods," International Journal of Biometeorology, vol. 58, no. 1, pp. 7-15, 2014.

[13] A. G. Shabeeb, et al., "Remote monitoring of a premature infants incubator," Indonesian Journal of Electrical Engineering and Computer Science, vol. 17, no. 3, pp. 1232-1238, 2020.

[14] Z. Lu, et al., "Silk fabric-based wearable thermoelectric generator for energy harvesting from the human body," Applied Energy, vol. 164, pp. 57-63, 2016.

[15] S. H. Woo, et al., "Body temperature predicting Patch-Type telemedicine system," IEICE Electronics Express, vol. 6, no. 16, pp. 1161-1167, 2009.

[16] S. S. Thomas, "Sensing Heart beat and Body Temperature Digitally using Arduino," in International conference on Signal Processing, Communication, Power and Embedded System (SCOPES), pp. 1721-1724, 2016.

[17] W. He, et al., "Recent development and application of thermoelectric generator and cooler," Applied Energy, vol. 143, pp. 1-25, 2015.

[18] Sudhindra F., et al., "Development of Real Time Human Body Temperature (Hypothermia \& Hyperthermia) Monitoring \& Alert System with GSM \& GPS," International Jurnal of Innovative Research in Science, Engineering and Technology, vol. 5, no. 6, pp. 9355-9362, 2016.

[19] Y. Wang, et al., "Wearable thermoelectric generator for harvesting heat on the curved human wrist," Applied Energy, vol. 205, pp. 710-719, 2017.

[20] S. Marathe, et al., "A Wireless Patient Monitoring System using Integrated ECG module, Pulse Oximeter, Blood Pressure and Temperature Sensor," in 2019 International Conference on Vision Towards Emerging Trends in Communication and Networking (ViTECoN), pp. 1-4, 2019.

[21] G. Jin, et al., "Design of Non-Contact Infra-Red Thermometer Based on the Sensor of MLX90614," The Open Automation and Control Systems Journal, vol. 7, no. 1, pp. 8-20, 2015.

[22] E. D. Bolat, "Implementation of Matlab-SIMULINK Based Real Time Temperature Control for Set Point Changes," International Journal of Circuits, Systems and Signal Processing, vol. 1, no. 1, pp. 54-61, 2007.

[23] J. Baruah, et al., "Microcontroller Based Temperature Monitoring and Controlling System," International Journal of Advanced Information Science and Technology (IJAIST), vol. 3, no. 6, pp. 38-42, 2014.

[24] S. Saha and A. Majumdar, "Data Centre Temperature Monitoring with ESP8266 Based Wireless Sensor Network and Cloud Based Dashboard with Real Time Alert System," in Devices for Integrated Circuit (DevIC), pp. 307-310, 2017. 
[25] H. M. Thwe and H. M. Tun, "Patient Health Monitoring Using Wireless Body Area Network," International Journal of Scientific and Technology Research, vol. 4, no. 06, pp. 364-368, 2015.

[26] O. O. Oluwgbenga, "Architecture Integrating Wireless Body Area Networks with Web Services for Ubiquitous Healthcare Service Provisioning," International Journal of Health and Medical Engineering, vol. 6, no. 12, pp. 1571-1578, 2012.

[27] N. A. J. Salih, et al., "Design and implementation of a smart monitoring system for water quality of fish farms," Indonesian Journal of Electrical Engineering and Computer Science, vol. 14, no. 1, pp. 44-50, 2019.

[28] F. Hashim, et al., "Implementation of embedded real-time monitoring temperature and humidity system," Indonesian Journal of Electrical Engineering and Computer Science, vol. 16, no. 1, pp. 184-190, 2019.

[29] D. R. P. Patnaikuni, "A Comparative Study of Arduino, Raspberry Pi and ESP8266 as IoT Development," International Journal of Advanced Research in Computer Science, vol. 8, no. 5, pp. 2350-2352, 2017.

[30] A. A. Rahimoon, et al., "Design of parabolic solar dish tracking system using arduino," Indonesian Journal of Electrical Engineering and Computer Science, vol. 17, no. 2, pp. 914-921, 2020.

[31] I. A. Sohu, et al., "Analogous study of security threats in cognitive radio," in 2019 2nd International Conference on Computing, Mathematics and Engineering Technologies (iCoMET), pp. 1-4, 2019.

\section{BIOGRAPHIES OF AUTHORS}
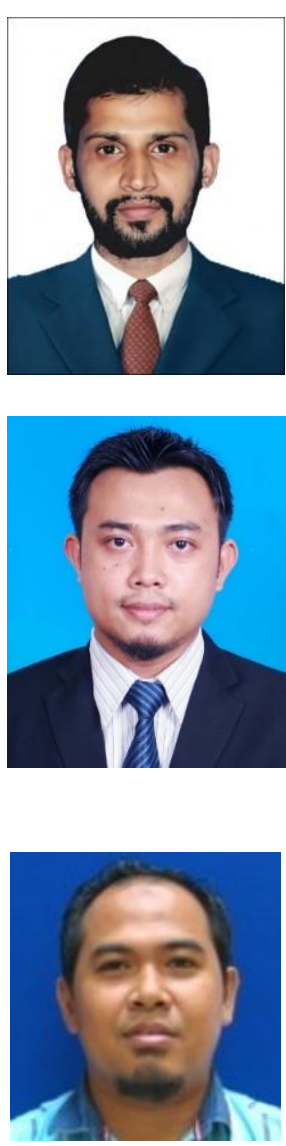

Asif Ahmed received his B.Eng. in Electronics Engineering and M. Eng. in Electrical Power Engineering from Mehran University Jamshoro, Pakistan (MUET) in 2014 and 2018 respectively. He is currently pursuing his Ph.D degree in Electrical Engineering from University of Tun Hussein Onn Malaysia (UTHM). He has been with Indus University Karachi from 2017 to 2018 as a Lecturer in Department of Electrical technology, Faculty of Science and Technology (FEST). His research interests include power distribution and generation, electric power dispatch and renewable energy.

Dr. Mohd Noor Abdullah received his B.Eng. (Hons) in Electrical Engineering and M. Eng. in Electrical Engineering (Power System) from Universiti Teknologi Malaysia (UTM) in 2008 and 2010 respectively. He also received a Ph.D degree in Electrical Engineering from University of Malaya (UM) in 2014. He has been with Universiti Tun Hussein Onn Malaysia (UTHM) from 2008 to 2014 as a tutor. He is currently as a Lecturer in Department of Electrical Power Engineering, Faculty of Electrical and Electronic Engineering (FKEE), Universiti Tun Hussein Onn Malaysia (UTHM). He also appointed as a head of Green and Sustainable Energy (GSEnergy) Focus Group in FKEE, UTHM. He was a member of Board of Engineer Malaysia. He also a certified of qualified person of SEDA Malaysia Grid Connected Photovoltaic System design. His research interests include electric power dispatch, distributed generation, renewable energy and meta-heuristic optimization techniques.

Ts. Dr Ishkrizat Bin Taib graduated from the Universiti Teknologi Malaysia, with a Bachelor Degree in Mechanical Engineering. He joining Universiti Tun Hussein Onn Malaysia as a lecturer in 2016. He obtained a M.Sc. in Mechanical Engineering from the Universiti Teknologi Malaysia in 2010 and a Ph.D. in the area of Biomechanic in 2015 from the Universiti Teknologi Malaysia (UTM). He is now a Professional Technologist of the Malaysia Board of Technologist, Malaysia. His current research interest is in Biomedical Engineering, Flow and Energy Modelling. 